idealistic perfection, our's of the practical care of children.

Finally, a standard dosage regimen recommended for nitrofurantoin is $7 \mathrm{mg} / \mathrm{kg} / 24$ hours. ${ }^{1}$ For a 2-year-old weighing approximately $12 \mathrm{~kg} 75 \mathrm{mg}$ per day is not excessive. Not being blessed with foresight, we were not able to foresee the results from Professor de Wardener's department that Dr. Bailey refers to, ${ }^{2}$ as these had not been published at the time we drafted our article, let alone at the time we were treating the child concerned.-We are, etc.,

R. H. JACKSON

Children's Department, Royal Victoria Infirmary,

Newcastle upon Tyne

Nelson, W. E., Textbook of Paediatrics, 8th ed. P. 223. $R$. E

de Wardener, H. E., Lancet, 1971, 2, 1112

\section{Recurrent Urinary Infections}

SIR,-I would like to agree with Dr. H. G. Jones (8 April, p. 113) that it is to be regretted that his regional board does not consider it essential to equip the new district general hospital with tomographic units for excretory urograms. Although there are only one or two centres, so far as I am aware, who now use routine tomography during excretory urography, I am certain that a urogram without tomography will soon be considered an incomplete and unsatisfactory examination. In a recent study using routine tomography in 423 excretory urograms we found that under the age of 40 routine tomography showed a distinct improvement in just over half the patient in both sexes, whereas over the age of 40 there was a further substantial improvement, particularly in males.

As for the bogey of expense, tomography tables are not expensive when considered as a capital outlay, particularly in terms of the usual high cost of radiographic equipment I am quoted a figure of approximately $\$ 5,000(£ 2,000)$ as the difference between a routine and tomographic unit.-I am, etc.,

Peter DURE-Smith

Thomas Jeศerson Unirersity Hospital,

Philade!phia, Pa., U.S.A.

1 Dure-Smith, P., and McArdle, G. H., British ournal of Radiology, 1972, in press.

\section{Depressive Illness and Aggression in Belfast}

Sir,-Drs. J. R. Ashton (11 March, p. 692) and D. Walsh (8 April, p. 115) suggest that the decrease in depression in Belfast in 1970, as described in my paper on aggression and depression in Belfast (5 February, p. 342) could be due to patients being unable to contact their doctors because of the disruption in normal life. In reply to this suggestion I would like to make the following points.

In spite of constant civil disturbance in Belfast in recent years communication between patient and doctor has not been affected to any appreciable extent. Both general practitioners and consultants can move freely throughout the citv, and generally patients have no great difficulty in artending surgeries and outbatient clinics. The number of parients attending peychiatric outbatient clinics in Belfast has not shown any significant decrease in recent vears-the range from 1964-71 being 699-1,035 new- patient attendances per annum and 3,3214,389 re-attendances per annum, the respecive figures for 1970 being 985 and 4,389 (figures obtained from the Statistics Branch of the Northern Ireland Hospitals Authority)

The number of admissions to Purdysburn Hospital (the main mental hospital for Belfast) has been increasing in recent years. In the five-year period from 1964-8 inclusive there was an approximate $5 \%$ increase in the admission rate per year. In the past three years this annual increase has not occurred, the admission rate remaining fairly constant. The fact that the rising admission rate has been halted could be explained by the decrease in depressive illness in Belfast as demonstrated in my paper.

Furthermore, if the decrease in depressive illness was due to patients being unable to visit their doctors or being referred to psychiatrists, one would not expect the highly significant decrease in the suicide rate in 1970 and which continued to remain low in 1971 (figures obtained from the Registrar General's office, Belfast). -I am, etc.,

Purdysburn Hospital,

H. A. Lyons

Purdys

\section{Oral Prostaglandin $E_{2}$ for Induction of Labour}

SIR,-We wish to comment on some of the points made by $\mathrm{Mr}$. Ian Craft in his report on induction of labour by the oral administration of prostaglandin $E_{2}$ (22 April, p. 191). In our view, it is misleading to use the term "titration" in relation to oral administration of prostaglandin in the same sense as it has been used in relation to intravenous administration of oxytocin "Titration" of intravenous oxytocin involves rapid adjustment of the dosage in relation to the degree of uterine response. In contrast, oral doses of prostaglandin are given every two hours and the same degree of flexibility cannot be achieved. Furthermore, during "titration" with intravenous oxytocin the dose is progressively increased if uterine response is not adequate, whereas with oral administration of prostaglandin the occurrence of gastrointestinal side effects often sets a limit to the dose.

It is our practice to administer an initial dose of $0.5 \mathrm{mg}$ of prostaglandin $\mathrm{E}_{2}$. If vomiting or diarrhoea does not occur, the dose is increased to $1.0 \mathrm{mg}$ given every two hours. A maximum dose of $1.5 \mathrm{mg}$ may be given if the cervix is unripe. Administration of doses greater than $1.5 \mathrm{mg}$ is often associated with not only vomiting or diarrhoea but paradoxically also with inefficient uterine activity. Indeed, in the series reported by Mr. Craft in all three women who received doses of prostaglandin $E_{2}$ higher than $1.5 \mathrm{mg}$ (Case Nos. 23, 25, and 39) the occurrence of vomiting or diarrhoea was associated with poor uterine action. This poor uterine response may be due to lack of absorption following vomiting as has been suggested by the author. Alternatively, the phenomenon may be a form of tachyphylaxis. The possibility also exists that in these women there is a qualitative insensitivity of the myometrium to prostaglandin. Therefore the uterus fails to resnond to not only doses of prostaglandin $E_{2}$ between 0.5 and $1.5 \mathrm{mg}$, but also to higher dosage.

We would like to emphasize the need for close supervision and monitoring of the fetus in labour induced by oral administration of prostaglandin, not only because of any possible adverse effect of prostaglandins, but also because of the underlying risk factor which necessitated induction of labour.-We are, etc.,

Mill Road Maternity Hospital,

H. K. BASU

Liverpool

H. Thelwall-Jones

Liverpool Maternity Hospital,

Liverpool

\section{Diabetics and Motorway Crashes}

SIR,-Dr. G. E. Leyshon and others (13 May, p. 405) state that diabetics need not disclose their disability on their driving licence application form except if they suffer from disabling attacks of giddiness or fainting.

Perhaps my reading of the driving licence application form is different to theirs but, as a diabetic on oral therapy and one involved in research in this condition, I have always felt obliged to declare my condition in answer to question 7f. This question asks, "Are you suffering from any other disease or disability likely to cause the driving of a motor vehicle by you to be a source of danger to the public?" As I have never suffered from an attack of hypoglycaemia I do not feel obliged to answer in the affirmative question $7 b$, "Do you suffer from or have you at any time had sudden attacks of disabling giddiness or fainting?" However, I take the view that should I unfortunately be involved in a road accident without having declared my condition both the licensing authority and my insurance company (for whom such information is obligatory) could render me liable on both counts for withho'ding such information. I do not find the licensing authorities present any difficulties apart from their asking, from time to time, for a medical certificate.

Therefore, it would seem to be in the interests of diabetics to declare their condition on their driving licence applicat on form to safeguard themselves. - I am, etc.,

Servier Laboratories Ltd.

N. SANTER

Harrow, Middx

\section{Condylomata Acuminata}

SiR,-I was interested in your leading article on "Condylomata Acuminata" (22 April, D. 179). At the West London Hospital a survey was made during 1970 of conditions of dermatological interest prosenting in the venereology department. The figures obtained for anal warts were not unlike those obtained by Oriel at St. Thomas's Hospital.

Perianal warts were seen in $154 \mathrm{male}$ patients of whom 126 were homosexual $(81.8 \%)$. It may be of interest that many of 28 heterosexual patients seen with per anal warts were also found to ha"e co-existent inguinal and penile warts, and in these cases the perianal warts were possibly secon'ary to the initial condvlomata acuminata elsewhere on the genitals.

Similarly during the same period it was noticed that anal warts were five times more common than penile warts in 402 homosexual males studied. This pores the quection of why are venile warts relatively uncommon among homosexuals? Although in the series 
studied at this hospital the homosexual proportion of patients was $16.8 \%$, that of penile warts in homosexuals (24) compared to those seen in heterosexuals (482) was only $5 \%$.-I am, etc.,

\section{MICHAEL WAUGH}

Department of Venereology, West London Hospital, Charing Cross Group of Hospitals, 1 Oriel, J. D., British fournal of Venereal Diseases,
1971, 47, 373.

SIR,-In your leading article on "Condylomata Acuminata" (22 April, p. 179) you mention the treatment of soft anogenital warts with podophyllin $10-25 \%$ in spirit. The irritan effect of strong podophyllin on the normal skin is of course well known, and the older standard technique of using $20-30 \%$ in liquid paraffin or similar bases had some disastrous effects if precautions were not taken to remove the agent after four hours. Although protection of the surrounding skin with soft paraffin may help, severe balanitis is still liable to occur, especially in the uncircumcised.

For many years now I have been treating such warts with $3 \%$ podophyllin in propylene glycol. The main advantages of this preparation is that the treatment can be carried out daily (with an orange stick) by the patient himself. The only instructions that I give to the patient are to wash the area first with soap and water, to apply a simple dusting powder after the application, and to stop treatment temporarily if the area is too inflamed.

If the warts are still present after about six applications, they are almost certainly too hard and cautery or diathermy will be necessary.-I am, etc.,

R. W. B. SCUTt

R.N. Hospital,

Gosport, Hants

\section{Chondromalacia Patellae}

SIR,-In your leading article on "Chondro malacia Patellae" (15 April, p. 123) you discuss many of the problems of pathogenesis diagnosis, and treatment of this condition, but you do not mention one important type of patello-femoral degeneration which may follow plaster treatment of lower limb fractures.

In assessing claims for damages following leg fractures I have been impressed with the frequency with which these patients subsequently complain of grating behind the patella. Such grating is not infrequently the most prominent complaint at the conclusion of treatment and it may be very difficult to estimate the significance of the symptoms. However, I am convinced that in the vast majority of cases this sequel is due to the effect of pressure of the plaster cast on the patella. The condition is therefore preventable. Prevention is a simple matter of cutting a window over the front of the patella thus allowing the patella to protrude through a hole in the plaster.

This type of plaster has been found to be more comfortable than the conventional plaster. Cutting the window is facilitated by first applying to the front of the knee a circular piece of orthopaedic felt 6 inches in diameter.

I have been so impressed with the effect- tiveness of this measure that I have not thought it justifiable to conduct a controlled trial. Such a trial would not be difficult in a large fracture unit, however.-I am, etc.,

Bridgend General Hospital,

A. W. FoWLER

Bridgend General
Bridgend. Glam

\section{Fat Embolism in Patients with Fractured Hips}

SIR,-As one of the co-authors of the article on fatal fat embolism following replacement arthroplasty for transcervical fractures of the femur (Dr. G. A. Gresham and others, 12 June 1971 , p. 617) I was interested to read Dr. I. Sevitt's article (29 April, p. 257). In the catchment area covered by our article Moore's arthroplasty was not performed and no comparison was possible between the use of a stemmed prosthesis with and without the use of acrylic cement.

During the last 18 months I have had access to six further cases of fat embolism in the East Suffolk area, in patients who died after fractures of the upper end of the femur. All were women. One had an intertrochanteric fracture and the rest subcapital fractures. The former and one of the latter did not have suffioient fat in the lungs to cause death, although they were both aged 87. Another patient died three days after injury from massive fat embolism before operative treatment had been carried out. A fourth patient died within six hours of a Thompson arthroplasty using cement. The remaining two patients died from massive fat embolism after Moore's anthroplasty without the use of cement. Both operations were done through a posterior approach. One was a woman of 74 who was operated on 10 days after her injury and died within 9 hours of operation. The other was aged 90 , operated on two days after an injury and died about 14 hours later. The amounts of fat in the lungs in both these patients were sufficient to have caused death.

These are only two instances of fatal fat embolism after an arthraplasty using stemmed prosthesis without cement, but it does indicate that the complication exists. I believe that it will prove to be more common if the pathological changes are searched for routinely as the overall mortality rate after the various prosthetic procedures is very similar. ${ }^{1}$-I am, etc.

Ipswich and East Suffolk Hospital,

D. Rosborougr

Ipswich

Hunter, G. A., British fournal of Surgery, 1969

\section{Total Replacement of the Hip}

SIR.-Your leading article (22 April, p. 177) reflects the present enthusiasm for total hip replacement, and it is not surprising that an operation which results in up to $90 \%$ of patients being completely relieved of their symptoms ${ }^{1}$ should be so acclaimed. However, we feel that some caution is necessary when contemplating reconstructive joint surgery involving the use of acrylic cements.

There have been many reports in the British literature ${ }^{2-6}$ of acute hypotension and of fatalities associated with the application of methylmethacrylate cement during total hip replacement, and similar reports have now appeared from the U.S.A. ${ }^{78}$ where the clinical use of this substance has only lately been allowed. A recent investigation showed that the liquid component of the commercially available cements was the cause of the cardiovascular disturbance.

Transient hypotension was shown to be the main effect which was compensated by an increase in cardiac output. Those patients who have a fixed cardiac output are therefore specially at risk if methylmethacrylate cement is used. The liquid component consists of monomeric methylmethacrylate with small amounts of hydroquinone, dimethylparatoluidine, methanol, methacrylic acid, and water. Our recent (as yet unpublished) work demonstrated unequivocally that methylmethacrylate alone is responsible for the hypotension.

There is no place for a complacent attitude when considering those operations during which large amounts of this acrylic cement are applied to vascular bone surfaces, and it is to be hoped that an innocuous cement compound will be developed as an alternative to methylmethacrylate. Until then, as already stressed by Charnley and his colleagues, ${ }^{9}$ the $N$ most cautious selection of patients is or essential so that only those in whom the advantages of the procedure outweigh the dangers of its performance are submitted to $\frac{\mathrm{S}}{\mathrm{S}}$ operations using large amounts of bone $N$ cement.-We are, etc.,

Department of Anaesthesia,

RICHARD H. ELLIS James Mulvein St. Bartholomew's Hospital, London E.C.1

1 Charnley, J., fournal of Bone and foint Surgery, 1972, 54B, 61

Powell, J. N., McGrath, P. J., Lahiri, S. K. and Hill, $P$., British Medical fournal, 1970, 3, 326 Ling, R. S. M., and James, M. L., British Medical Fournal, 1971, 2, 404.

(1. C., and WaterPhillips, H., Cole, P. V nesia, 1971, 26, 298. British Medical foumal $1971,3,460$. Peebles, D. J., Ellis, R. H., Stride, S. D. K. S and Simpson, B. R. J., British Medical fournal, $1972,1,349$.

7 Cohen, C. A. and Smith, T. C., Anesthesiology, $1971,35,54$;

Newens, A. F. and Volz, R. G., Anesthesiology,
1972, 36, 298. $1972,36,298$.

Charnley, J., Murphy, J. C. M., and Pitkeathly,

ABO Blood Groups and Sex Ratio at Birth

SIR,-In a series of 264 ABO blood-grouped white newborn babies and their mothers reported in 1925 Hirszfeld and Zborowski ${ }^{1}$ observed that the sex ratio-that is, the ratio of males to females-was higher for babies of mothers of blood group AB than for babies of mothers of the combined blood groups $\mathrm{A}, \mathrm{B}$, and $\mathrm{O}(\mathrm{P}<0 \cdot 05)$. They declared that "if this finding were confirmed it would have far-reaching theoretical significance," and in view of this it is interesting that, as the Table shows, the difference they observed obtains $(\mathrm{P}<0.01)$ in the aggregate, totalling 45,645 cases, of all 15 of the white series reported in 1924-72.1-4 (This aggregate includes a personal series of 14,451 cases, of whom 5,612 were reported previously. ${ }^{3}$ ) Further, in a series reported in 1951 Sanghvi ${ }^{2}$ observed that the sex ratio was higher for $B$ babies of $B$ mothers and $O$ babies of $O$ mothers than for $A$ babies of A mothers, and the Table shows that the $\vec{c}$ same difference obtains in the 1924-72 aggregate.

The Table shows also a new finding, in that the difference observed by Sanghvi is, in this aggregate, accompanied by a differ- 